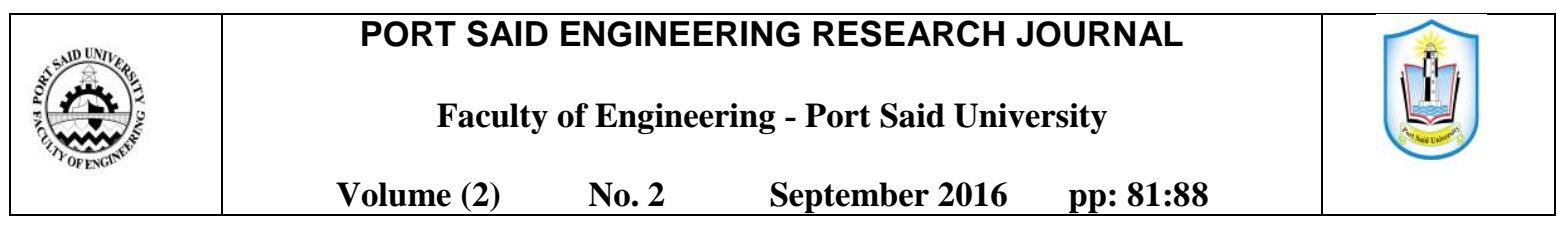

\title{
Applications of GIS in Flood Control and Crises Management Using Different Sources of DEMs in Al Arish, Sinai, Egypt
}

\author{
A. Amin ${ }^{1}$, A. El Hattab², M. El Bastawesy ${ }^{3}$, A. Sharawi ${ }^{4}$, Marwa Azzam ${ }^{5}$
}

\begin{abstract}
The aim of this research is to provide an approach to identify the potential routes of water flood in the study area as well as its relevant area of containment (Al Arish, North Sinai, Egypt). The outcomes of the research shall help in early warning to avoid catastrophic damages to the community area and consequent fatalities, destruction of infrastructures and property losses. To obtain the best accuracy in this research the issue of flood hazard, vulnerability and risk mapping will be displayed from the perspective of different mapping scale in a GIS environment. GIS is extensively used to assemble information from different maps, remote sensing images and Digital Elevation Models (DEMs). However, in the current research, two Semi- Hydraulic Models (since Al-Arish area does not form a complete drainage basin, but it is considered as the outlet of drainage basin for Wadi Al-Arish which is located in the middle of Sinai Peninsula, so, time zones and hydraulic structures design are not included) are presented, namely: Interactive-GIS Based Model and Automated- GIS based Model.
\end{abstract}

Keywords: GIS, DEM, Resolution, Topographic Maps, Network

\section{INTRODUCTION}

Flash floods create havoc among people. Their effect exists in agricultural sector. They affect private property as well as infrastructure, such as roads, drainage system, etc. There are two types of damages caused by a flash flood, i.e. direct and indirect damages (Bunn and Arthington, 2002).

Direct damages caused by high speed of floodwater include:

1. Destruction of the drainage system in the cities.

2. Water contamination with chemical waste, paint, pesticide, gasoline, etc.

3. Drowning of people, pets and animals.

4. Destruction of farmland and crops.

Figure (1) shows stages of flash floods in three steps:

1. heavy rain falls onto waterlogged ground.

2. rainfall cannot fully infiltrate into the ground, so large amounts runs downstream.

3. rivers rises dramatically and bursts its banks, flooding valley floor.

1 Prof. of surveying, Civil Eng. Dept., Faculty of Engineering, Suez Canal University, Egypt.

2 Prof. of surveying, Civil Eng. Dept., Faculty of Engineering, Port Said University, Egypt.

3 Associate Prof. Head of the Geological application department, Geology division, (NARSS), Cairo, Egypt.

4 Researcher, Aerial Photography and Aviation Department, National Authority for Remote Sensing and Space Sciences (NARSS), Cairo, Egypt. 5 Demonstrator, Civil Eng, Dept., Faculty of Engineering, Port Said

University, Egypt..

E-mail address:Mazzam4444@gmail.com

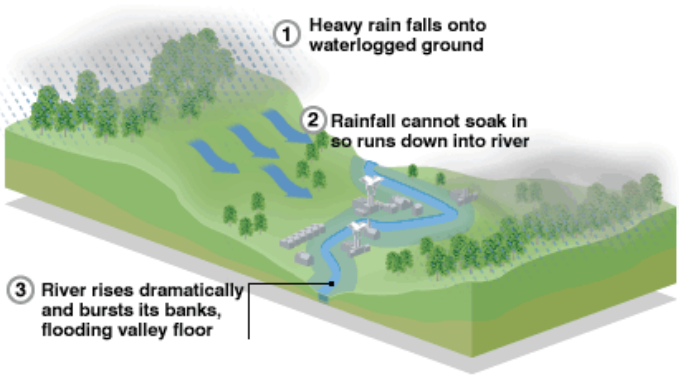

Figure 1: Occurrence of Flash Floods

(Bunn and Arthington, 2002)

GIS is used to help in modelling the occurrence of disaster. It can be used in structural and non structural mitigation. GIS allows to spatially represent areas at risk and the level of risk associated with a particular hazard which can be a guide in making decision. It will facilitate the implementation of necessary mechanisms applied to lessen the impact of a potential emergency. With GIS, disaster managers are in a better position to determine the level of mitigative structures that should be in place given the vulnerability of an area or population.

\section{TEST AREA AND DATA SETS}

\subsection{Description of Test Area}

In this investigation, the GIS flood risk mapping project are presented through (Al Arish) in North Sinai. A map of Scale 1: 25k available from Egyptian General Surveying authority (EGSA) (figure 2). 


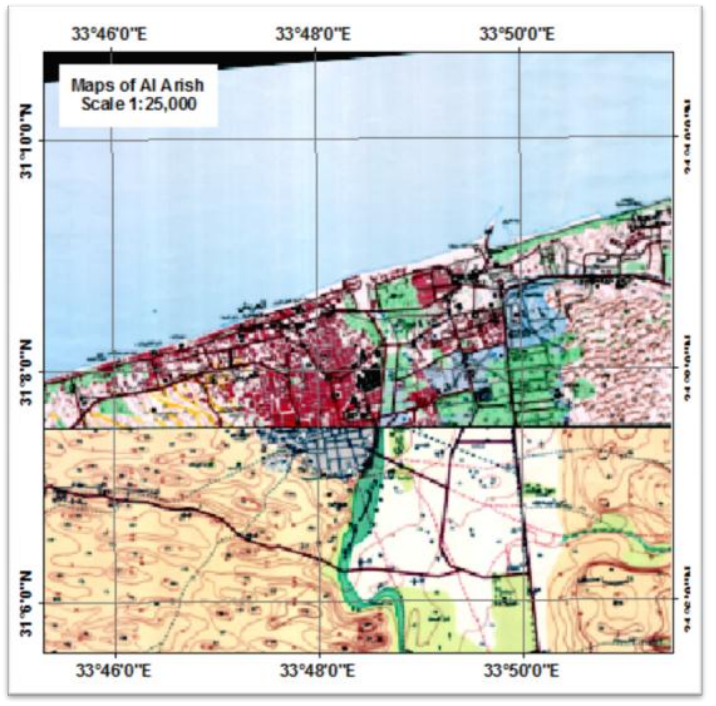

Figure 2: A map of Scale 1: 25k of AL Arish (EGSA)

Al-Arish image in the north of Sinai covers the ground area between the geographic coordinates $\left(33^{\circ} 46^{\prime} 50.56^{\prime \prime}\right.$ E, $\left.31^{\circ} 8^{\prime} 38.37^{\prime \prime} \mathrm{N}\right)$ to $\left(33^{\circ} 51^{\prime} 15.92^{\prime \prime} \mathrm{E}, 31^{\circ} 9^{\prime} 29.93^{\prime \prime}\right.$ $\mathrm{N})$. The main features in the area are the Mediterranean Sea, and the main road that is near to the sea which is connected to the East of Port Said.

Al Arish area has been exposed for several floods where the latest one was in Jan. 2010, affecting on the existing constructions, and subsequent impact on the lives of population.

This area is a residential zone and it has been severely hit and affected by the flood. It is considered as the outlet of drainage basin for Wadi Al-Arish which is the largest in North Sinai. The hydrological analyses are needed for further consideration to avoid damages to the infrastructure or installations and resulting potential fatalities.

This area has been studied with provision of a "Semi Hydraulic Model", since Al-Arish area does not form a complete drainage basin, but it is considered as the outlet of drainage basin for Wadi Al-Arish which is located in the middle of Sinai Peninsula.

The study came up with the identification of the flood water drain network for the area (Streams). This has been adopted for several resources of Digital Elevation Models (DEMs). They are compared and then analyzed to identify the most accurate and reliable resource to be considered as the main term of reference for other DEM calculations.

\subsection{Acquisition of DEMs by Different Techniques}

Three sources for acquisition of DEMs are used.

First: open source data archive ASTER DEM (figure 3).

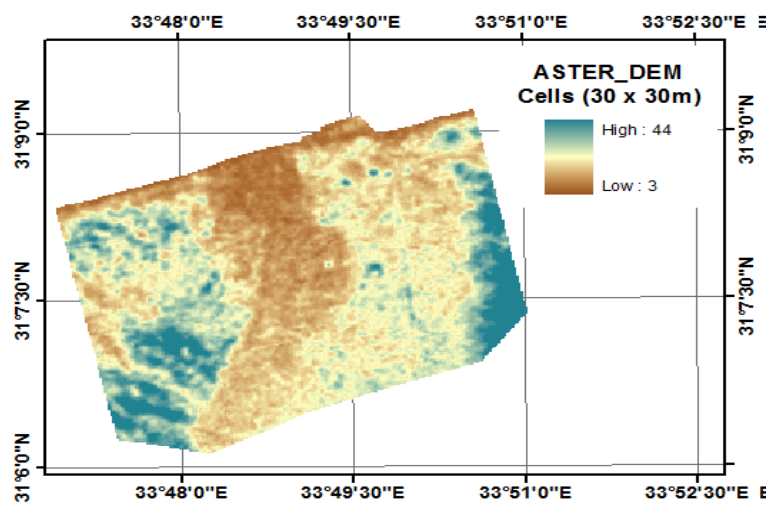

Figure 3: ASTER DEM of Al-Arish study area

Second: Digitizing topographic maps of scale 1:25,000 to extract: the layers of contour and point's elevation (figure 4), relevant 30m DEM (figure 5) as well as the corresponding GeoEye-1 satellite image (figure 6).

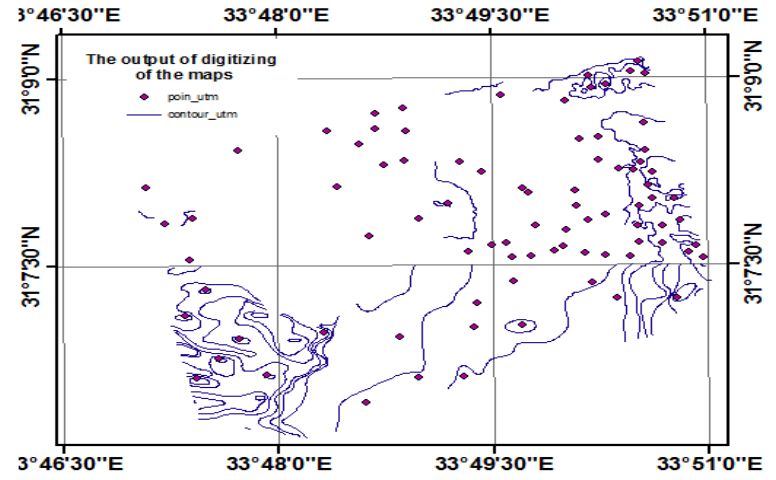

Figure 4: Points and Contour Layer

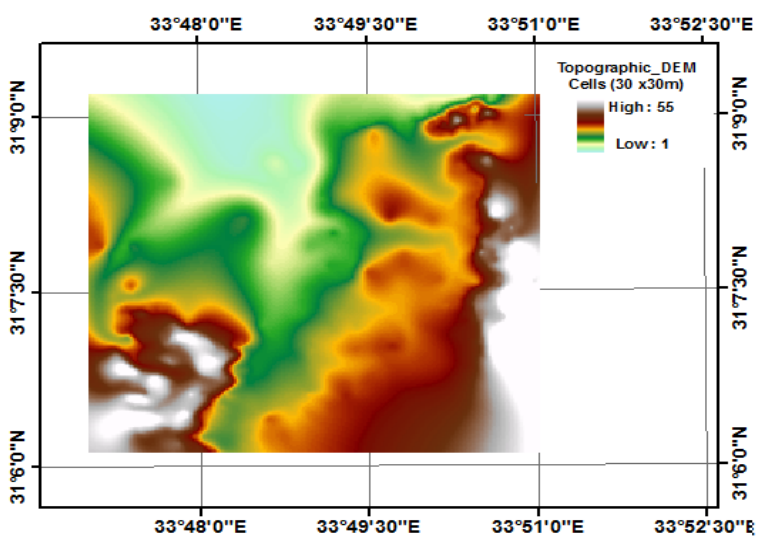

Figure 5: Topographic DEM cell size 30m of Al Arish 


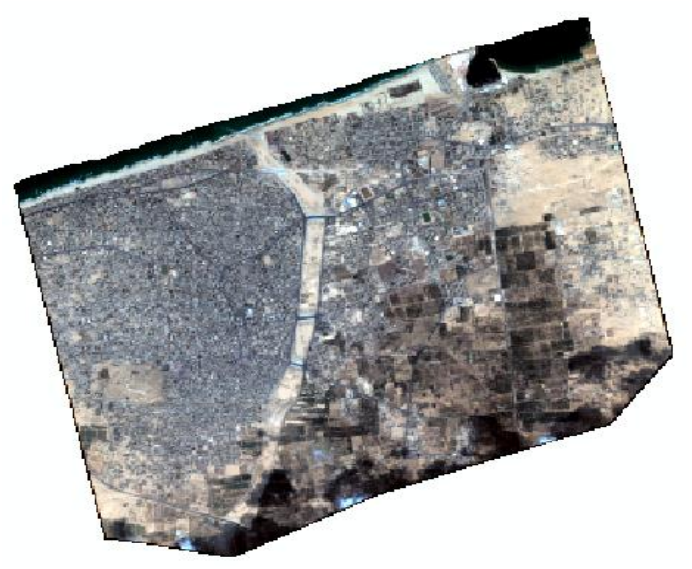

Figure 6: GeoEye-1 satellite image of Al-Arish study area

Third: Creation of DEM for the study area using GeoEye-1 Stereo High Resolution Images (figure 7), geo-referenced by some pre-defined three-dimensional ground control points which have description cards using Erdas Imagine Software Package (table 1).

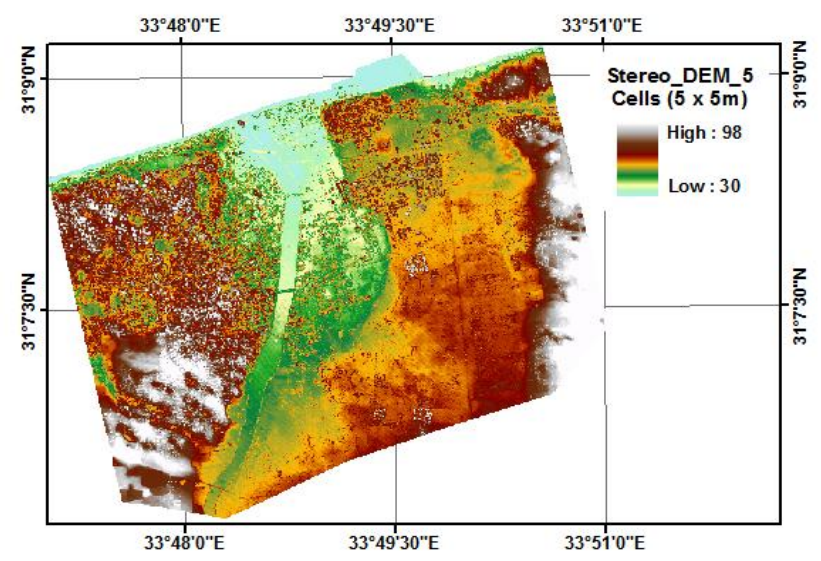

Figure 7: DEM cell size 5m created from GeoEye-1 Stereo High Resolution Images

Table 1: Ground Coordinates $(X, Y, Z)$ of the Ground Control Points (Old Egyptian Datum: Projection ETM + Helmert Ellipsoid1906) \& Corresponding WGS-84 Datum.

\begin{tabular}{|c|c|c|c|}
\hline & \multicolumn{3}{|c|}{ ETM } \\
\hline Point & E & N & Height \\
\hline G008 & 187555.378 & 1226992.279 & 41.998 \\
\hline G009 & 187474.694 & 1224405.704 & 44.356 \\
\hline G011 & 185016.586 & 1226185.964 & 46.991 \\
\hline & \multicolumn{3}{|c|}{ UTM } \\
\hline G008 & 578258.8 & 3445420 & 42 \\
\hline G009 & 578224.9 & 3442834 & 44.36 \\
\hline G011 & 577237.4 & 3445025 & 46.99 \\
\hline \hline
\end{tabular}

\section{INTERACTIVE-GIS BASED MODEL}

To analyze these DEMs, automatic processing techniques and relevant steps used in hydraulic models (streams and drainage networks workflow delineation), were followed (Rodriguez-Itrube et al., 1989). Figures (8, 9 and 10) show the output for the three DEMs used.

\subsection{Hydrographic Analyses of DEMs}

The automatically extracted drainage networks for the same study area give different outputs. Regarding the $30 \mathrm{~m}$ topographic DEM and 5m stereo DEM give a consistent results, showed that the two main Wadies in the area (see stream networks) are flowing northward. This flow direction is true for Wadi Al Arish (on the left side) and can be verified from both the DEM itself and the satellite image. Regarding the ASTER DEM, the output gives a contradicting results concreting the other Wadi in the area (on the right side to the east of Wadi al Arish main trunk). However, on-ground flow direction for this contradicting channel on the different DEMs cannot be verified in the field.

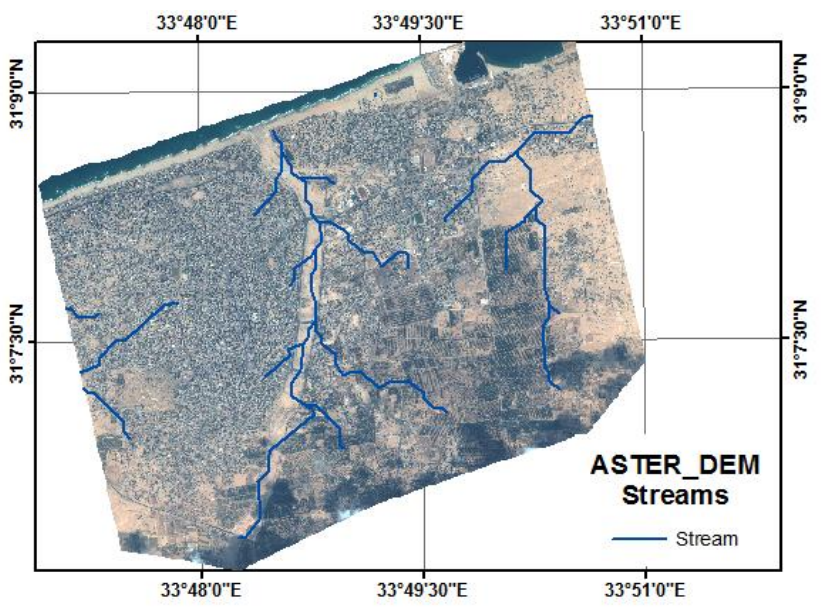

Figure 8: Networks and paths (Streams) for the basin in Al Arish output from ASTER DEM

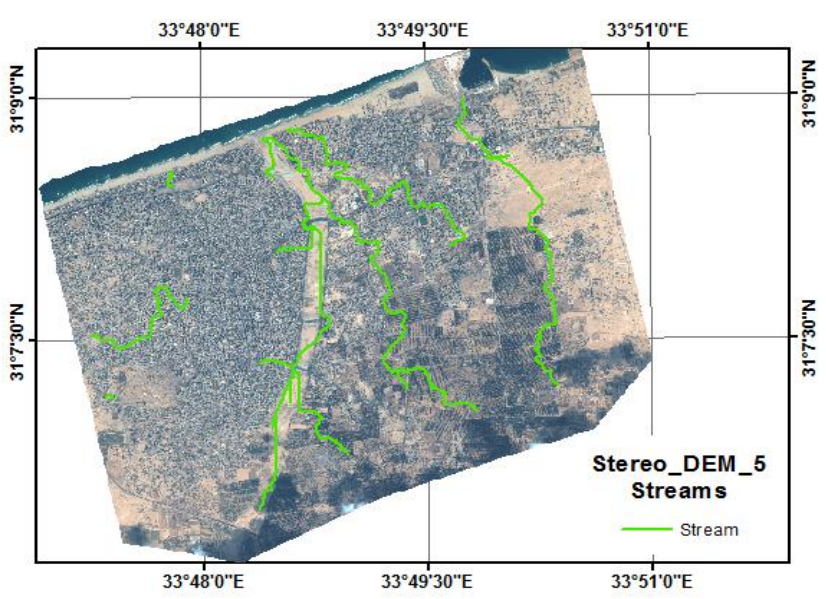

Figure 9: Networks and Paths (Streams) for the basin in Al Arish output from Stereo DEM 5m 


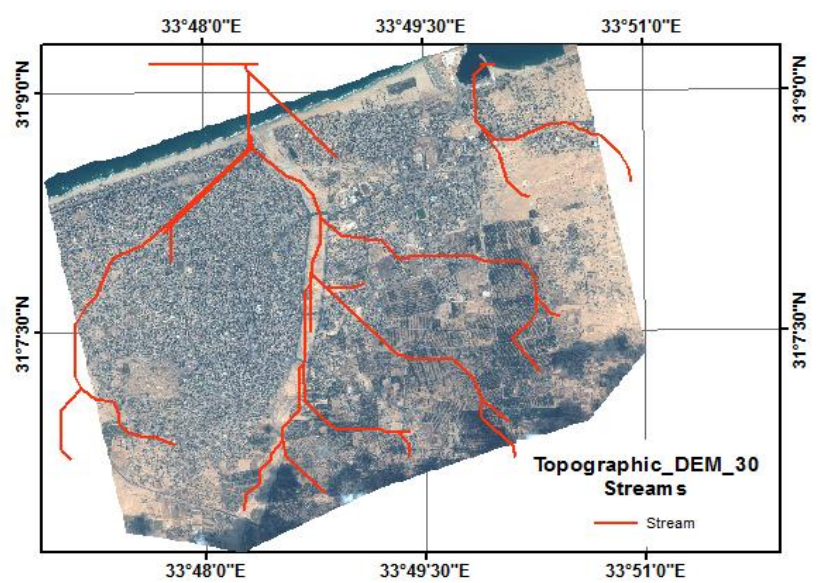

Figure 10: Networks and Paths (Streams) for the basin in Al Arish output from Topographic DEM 30m

\subsection{Sensitivity Analyses}

From the previous outputs, table 2 summarizes the different orders resulted from different stream orders of different sources of DEMs.

Table 2: The Stream Orders resulted from Different DEM Sources.

\begin{tabular}{|c|c|c|c|c|}
\hline Sources & $\begin{array}{c}\text { Order No. 1 } \\
\text { Smallest } \\
\text { streams } \\
\text { (pixel) }\end{array}$ & $\begin{array}{c}\text { Order No. 2 } \\
\text { (pixel) }\end{array}$ & $\begin{array}{c}\text { Order No. 3 } \\
\text { (pixel) }\end{array}$ & $\begin{array}{c}\text { Order No. 4 } \\
\text { Largest } \\
\text { streams } \\
\text { (pixel) }\end{array}$ \\
\hline ASTER & 417 & 197 & & \\
\hline Stereo DEM 5m & 2534 & 1726 & 204 & \\
\hline Topo DEM 30m & 409 & 395 & 124 & \\
\hline Topo DEM 5m & 2538 & 1332 & 307 & 501 \\
\hline
\end{tabular}

The main differences between the extracted drainage networks from multiple DEM appear only at the number and distributed fingertips of the channels (i.e. first orders). However, these changes in the first order channels slightly reflect on the morphometrical properties of the entire network downstream (i.e. ordering, bifurcation, ratio, stream frequency, and density).

\subsection{Results}

- The automatically extracted stream and drainage networks using different DEMs for the study area are not matching.

- The 5m stereo DEM gives a consistent result with its counterpart of the $30 \mathrm{~m}$ topographic one.

- The ASTER DEM gives a contradicting results concreting the other Wadi to the east of Wadi al Arish main trunk.
- The reliability of DEM in the landform and hydrographic analysis will depend on the combined parameters of source, resolution and verification.

- The quality of hydrological analysis varies from place to another among the different DEMs.

- The ASTER DEM is different from the other two DEMs, namely: interpolated 30m and 5m DEM from topographic maps and the $5 \mathrm{~m}$ stereo DEM.

- Extracted stream and drainage networks are consistent with the naturally existing main channels. So the route of flash flood discharge must kept clear of any occupations and obstacles. Additionally a full Hydrological model is needed for the wadi of Al Arish in order to estimate the problem of flash floods and required mitigation measures in according to 2010 flood event.

\section{Automated- GIS based Model (GOOGLE EARTH IMAGES + SPOT HEIGHTS)}

A program with GIS programming ArcObjects has been performed by using the vb.net language. It is a standalone inter-face which dealing with Google Earth's images as shown in figure (11).



Figure 11: Flow chart for Flood Management System of Al Arish

In this model, the input will be: satellite images as well as a grid of heights. Both are generated from Google Earth (figure 12). 




Figure 12: 3-D Satellite Image of Al Arish from Google Earth

In this context, four layers that will be inserted in the GIS Program, are prepared:

1. Image (Mosaic) layer (figure 13).

2. Spot heights (grid of points) layer (figure 14).

3. Buildings layer (figure 15).

4. Area of Interest (AOI) layer (figure 16).

During the Google Earth is being active, the image of ALArish area is called from GIS (Fedra, 1993, Skidmore, 2002, Peng and Tsou, 2003, Jiang and Yao, 2006). If the image is (black \& white) with (*.jpg) extension and low resolution, it implies obtaining a colored image, so we have to copy it through Google Earth and saving it as a (*.tiff) extension and high resolution.

Next, both images are inserted into the software of the GIS and applied georeferencing for the colored image to obtain the relevant coordinate system that enable to deal through GIS software and performing a projection to have a metric system dimension as well (Maguire, et al, 2005, Parker, et al, 2003, Dykes, et al, 2005, Bishop and Lange, 2005).

The previous step is repeated three times more to obtain four partially images with overlapped areas to make mosaic and get one image with high resolution. By recalling the image through the GIS, we get a (grid of points) with $\mathrm{z}$ (elevation), while it is opened identically in Google Earth with opening the terrain layer.

Then, a projection is performed in order to provide the same image coordinate system. It is necessary to recognize the building positions in order to create the flood routes around buildings. A total of 5500 buildings with assigned $(10 \mathrm{~m})$ as fixed height, with some systematic steps, the software process buildings as a part of the ground. So, the alternative solution is to remove the buildings and evacuating the part of the ground under and tagging as (Mask) then applying it to the rest of work.



Figure 13: The Google Earth Satellite image of Al-Arish after Georeferencing

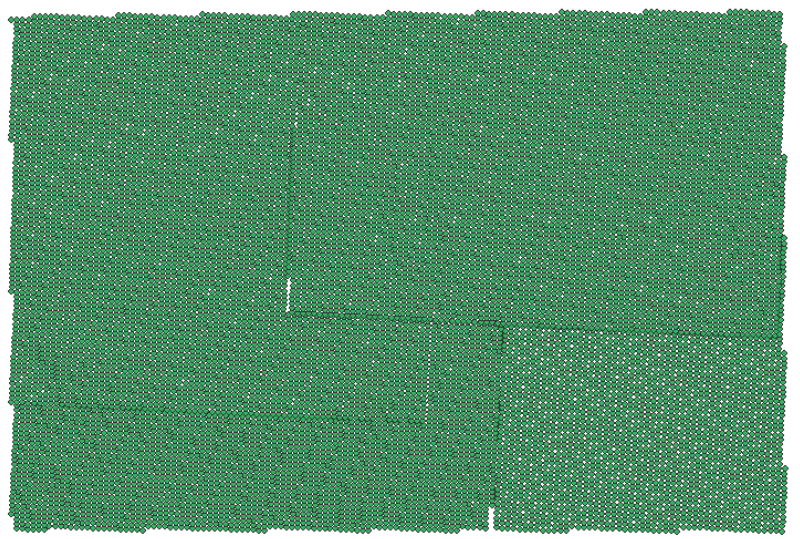

Figure 14: Spot Heights (grid of points) for the Image of Al Arish

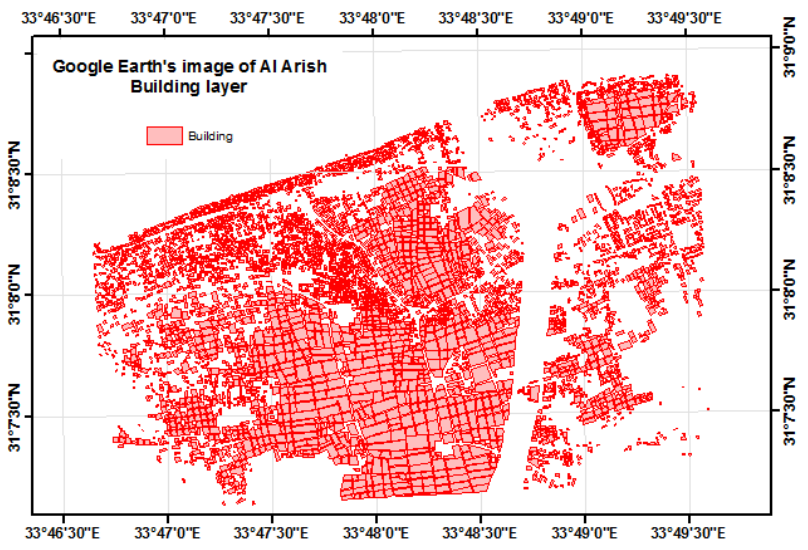

Figure 15: Layer of Buildings included in the Image of Al Arish 


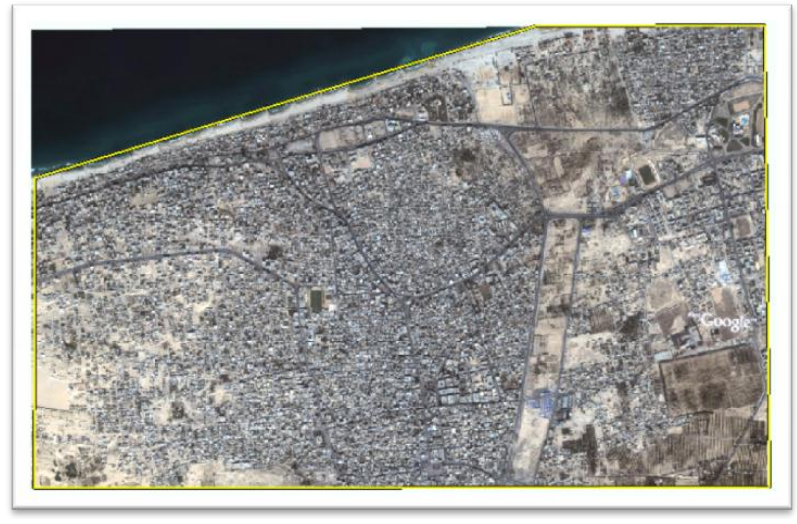

Figure 16: Area Of Interest (AOI) layer of AL Arish

\subsection{Processing of Hydraulic Model}

The results of the processing are shown in figures 17 to 21 .



Figure 17: DEM (Surface Interpolation) of Al Arish Google Earth Image

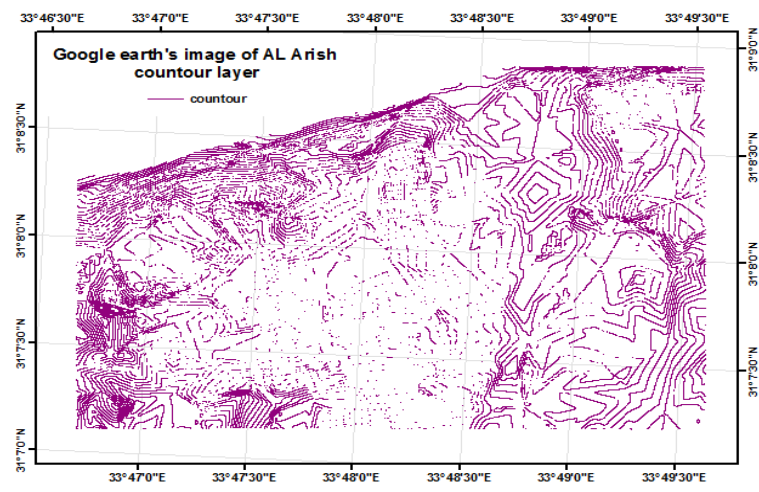

Figure 18: Contour Lines of Al Arish Google Earth Image

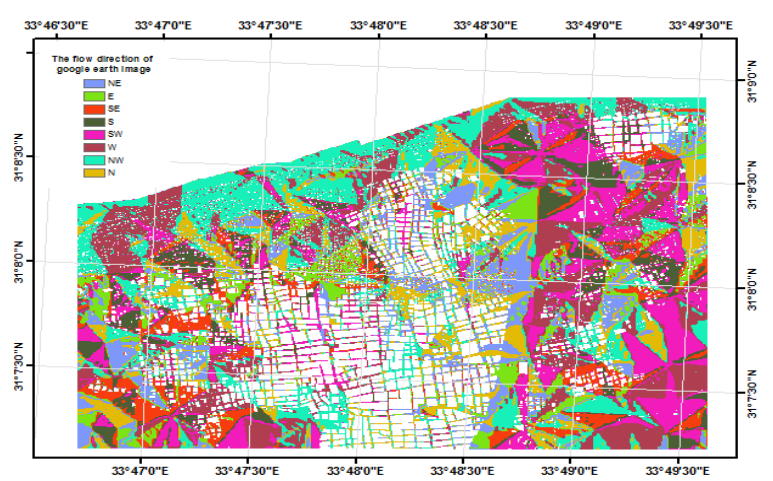

Figure 19: Flow Direction of Al Arish Google Earth Image

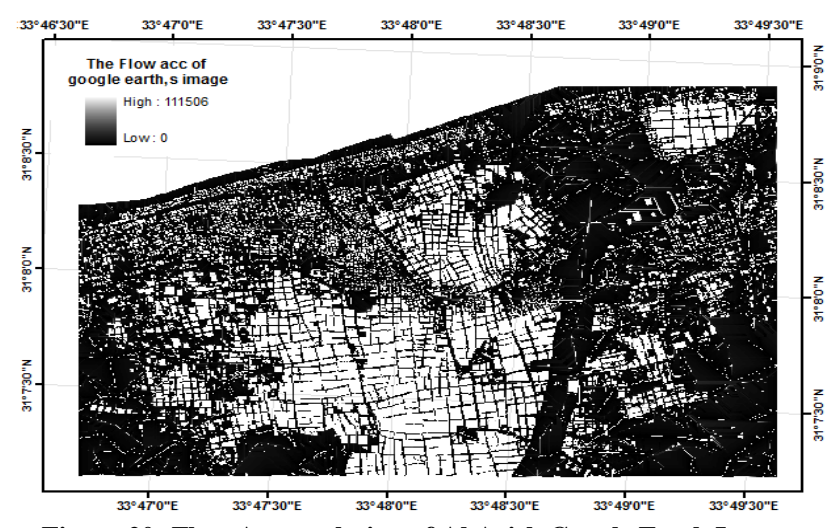

Figure 20: Flow Accumulation of Al Arish Google Earth Image

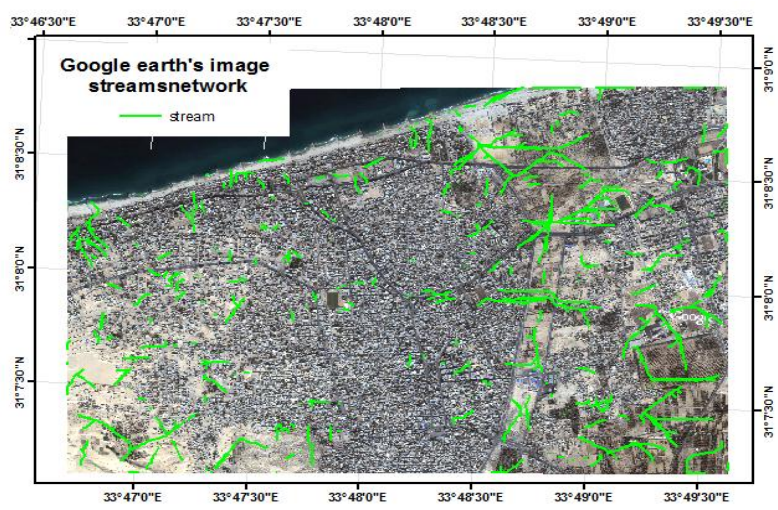

Figure 21: Flood Routes (Stream Network) Passing around Buildings of Al Arish Google Earth Image

\subsection{Simulation Check for The Generated Streams Network}

By using the last step "vectored network" for the expected streams for rain water flow between buildings according to the ground topography, then comparing it with a real DEM for this area it is discovered that it is approximately similar.

\subsubsection{Raising Up The Ground Water Level Using: Global Mapper Functions}

Trying to simulate raising up gradually the ground water level, discovering that the flood water final collection and containment area are approximately identical to the area of accumulation of the previously simulated raised up ground water as shown in figures 22 to 24 .

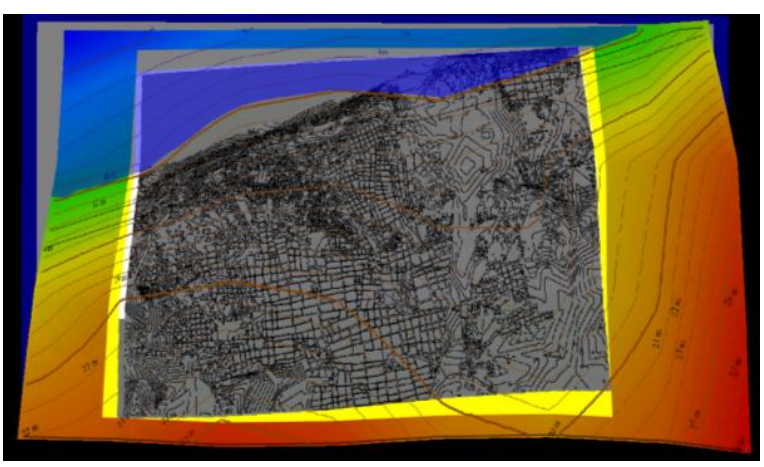

Figure 22: The $1^{\text {st }}$ step of Rising up Ground Water Level of Al-Arish Area 




Figure 23: The $2^{\text {nd }}$ step of Rising up Ground Water Level of AlArish Area

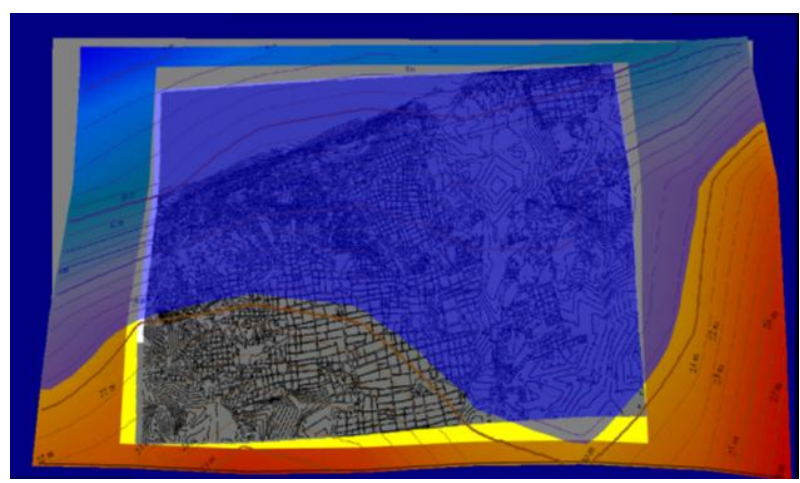

Figure 24: The $3^{\text {rd }}$ step of Rising up Ground Water Level of Al-Arish Area

The figures are showing the result of the streams network accumulation from the highest to the lowest level according to the topgraphy of the studied area versus the real "DEM" of the same area, consequently, both figures provided an approximitally identical result in terms of the final collection area of the flood.

\subsubsection{The Global Flood Map}

According to the Global Flood Map, Al Arish area appears in figure 25 , representing nearly the same result of the accumulation and the result of streams network for the studied area, which means that the results approximitally identical to the natural topography. (National Research Council, 2009 and State of North Carolina, 2008).

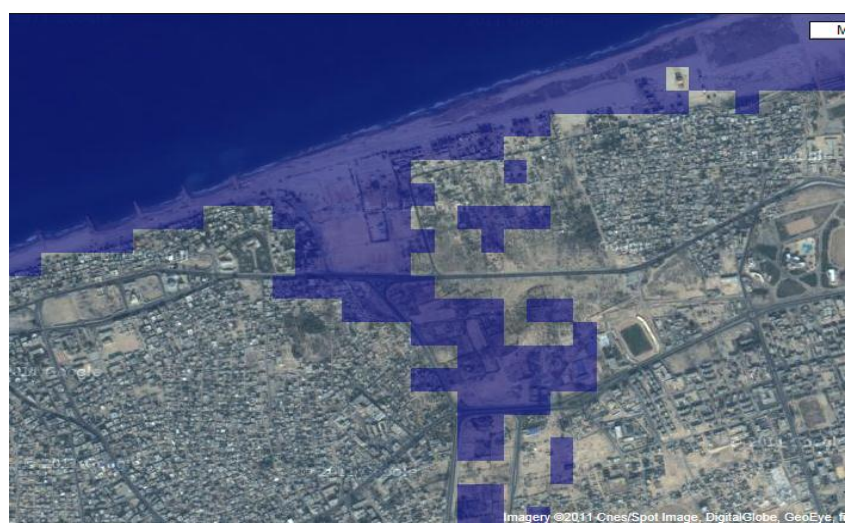

Figure 25: Global Flood Map - Al-Arish Area

\section{CONCLUSIONS}

- After Studying floods, relevant causes and resultant damages as well as studying the GIS system features, benefits and how to use it for limitation of the amount of water resulting from rains \& floods and how to use some techniques and features of this application through obtaining a satellite image of the area subject for study and analysis using the GIS application tools for image processing that can provide useful information about floods and rain water collection that could help to avoid expected damages, this is through developing a simple application of GIS using some specific tools.

- With reference to the previous results and outcomes, a flow chart has been developed to show how to proceed in such steps using the specific tools to achieve the best possible results in terms of using the flood water and reducing relevant caused damages.

- The developed program with GIS programming ArcObjects which performed in the current research, is considered a standalone inter-face one, that helps users and researchers to deal with Google Earth's images when they couldn't get satellite images with high resolution to obtain stream network for any study areas.

- The result of the streams network accumulation, from the highest to the lowest level according to the topography of the studied area versus the real "DEM" of the same area, both provided an approximately identical result in terms of the final collection area of the flood.

- From the global flood map, Al-Arish area representing nearly the same result of the accumulation and the result of streams network for the studied area, which means that the results approximately identical to the natural topography.

\section{RECOMMENDATIONS}

- It is utmost importance to evaluate the socioeconomic aspects of mitigation measures and harvesting of flash floods in order to achieve local sustainable development in the wadi systems.

- Prevent any construction for residential buildings in the path of flood drainages unless full protection is guaranteed upstream.

- Implementing a network for some flood paths to collect water in a specific locations where it could be used and take advantage of these water quantities.

\section{REFERENCES}

Bishop, I. and Lange, E., 2005. 'Visualization in Landscape and Environmental Planning', Taylor $\&$ Francis, Abingdon.

Bunn, SE., and Arthington, AH., 2002. 'Basic principles and consequences of altered hydrological regimes for aquatic biodiversity', Environmental Management, vol. 30, no. 4, pp. 492-507. 
Dykes, J.; MacEachren, A.M.; and Kraak, M-J., 2005.

'Exploring Geovisualization', Elsevier, Amsterdam.

Fedra, K., 1993. 'GIS and environmental modeling, in Goodchild', M.F., Parks, B.O., and Steyaert, L.T., Eds., Environmental Modeling with GIS, Oxford University Press, Oxford, 35-50.

Jiang, B., and Yao, X., 2006. 'Location-based services and GIS in perspective, Computers, Environment and Urban Systems', 30, 712-725.

Maguire, D.J.; Batty, M.; and Goodchild, M.F., 2005. 'GIS, Spatial Analysis and Modeling', ESRI Press, Redlands, California.

National Research Council, 2009. 'Mapping the Zone: Improving Flood Map Accuracy'. Washington DC: National Academies Press.

Parker, D.C.; Manson, S.M.; Janssen, M.A.; Hoffmann,

M.J.; and Deadman, P., 2003. 'Multi-agent systems for the simulation of land-use and landcover change: a review', Annals of the Association of American Geographers, 93, 314-337.

Peng, Z-R., and Tsou, M-H., 2003. 'Internet GIS: Distributed Geographic Information Services for the Internet and Wireless Networks', Wiley, Chichester.

Rodriguez-Itrube, I.; De Power, B.F.; Sharifi, M.B.; and Georgakakos, K.P., 1989. 'Chaos in rainfall'. Water Resources Research, 25, 1667-1675.

Skidmore, A., Ed., 2002. 'Environmental Modelling with GIS and Remote Sensing', Taylor \& Francis, London.

State of North Carolina, 2008. 'North Carolina Floodplain Mapping Program: 2000 - 2008', Program Review. State of North Carolina. 